\title{
Narrow-linewidth all-solid large-mode-area photonic crystal fiber amplifier
}

Hauge, Jakob Milo; Papior, Sidsel R.; Pedersen, Jens E. ; Christensen, Simon Lønborg; Bondu, Magalie; Alkeskjold, Thomas T.; Lægsgaard, Jesper

\section{Published in:}

Proceedings of spie

Link to article, DOI:

$10.1117 / 12.2506246$

Publication date:

2019

Document Version

Publisher's PDF, also known as Version of record

Link back to DTU Orbit

Citation $(A P A)$ :

Hauge, J. M., Papior, S. R., Pedersen, J. E., Christensen, S. L., Bondu, M., Alkeskjold, T. T., \& Lægsgaard, J. (2019). Narrow-linewidth all-solid large-mode-area photonic crystal fiber amplifier. In Proceedings of spie (Vol. 10897). [1089728] SPIE - International Society for Optical Engineering. Proceedings of SPIE - The International Society for Optical Engineering https://doi.org/10.1117/12.2506246

\section{General rights}

Copyright and moral rights for the publications made accessible in the public portal are retained by the authors and/or other copyright owners and it is a condition of accessing publications that users recognise and abide by the legal requirements associated with these rights.

- Users may download and print one copy of any publication from the public portal for the purpose of private study or research.

- You may not further distribute the material or use it for any profit-making activity or commercial gain

- You may freely distribute the URL identifying the publication in the public portal 


\section{Narrow-linewidth all-solid large- mode-area photonic crystal fiber amplifier}

Jakob M. Hauge, Sidsel R. Papior, Jens E. Pedersen, Simon L. Christensen, Magalie Bondu, et al.

Jakob M. Hauge, Sidsel R. Papior, Jens E. Pedersen, Simon L. Christensen, Magalie Bondu, Thomas T. Alkeskjold, Jesper Lægsgaard, "Narrow-linewidth all-solid large-mode-area photonic crystal fiber amplifier," Proc. SPIE 10897, Fiber Lasers XVI: Technology and Systems, 1089728 (7 March 2019); doi: 10.1117/12.2506246

SPIE. Event: SPIE LASE, 2019, San Francisco, California, United States 


\title{
Narrow-linewidth all-solid large-mode-area photonic crystal fiber amplifier
}

\author{
Jakob M. Hauge ${ }^{*}$,b, Sidsel R. Papior ${ }^{\mathrm{b}}$, Jens E. Pedersen ${ }^{\mathrm{b}}$, Simon L. Christensen ${ }^{\mathrm{a}, \mathrm{b}}$, \\ Magalie Bondu ${ }^{\mathrm{b}}$, Thomas T. Alkeskjold ${ }^{\mathrm{b}}$, and Jesper Lægsgaard ${ }^{\mathrm{a}}$ \\ ${ }^{a}$ DTU Fotonik, Technical University of Denmark, Ørsteds Plads, 2800 Kgs. Lyngby, Denmark \\ ${ }^{b}$ NKT Photonics A/S, Blokken 84, 3460 Birkerød, Denmark
}

\begin{abstract}
Large-mode-area (LMA) photonic crystal fiber (PCF) amplifiers are attractive for high-power amplification of single-mode (SM) narrow-linewidth light. Traditionally, LMA PCF designs include air holes but splicing and interfacing of fibers with air holes is complicated. Recently, this was addressed with the development of a LMA PCF amplifier fiber without air holes but with SM operation maintained. This all-solid fiber can be spliced with standard splicers and thus enables integration of PCFs into all-fiber monolithic laser systems.

The new fiber, named DC-250/30-PM-Yb-FUD, is demonstrated in a free-space configuration for high-power amplification of $1064 \mathrm{~nm}$ light with a narrow linewidth of less than $20 \mathrm{kHz}$. A seed power of $380 \mathrm{~mW}$ is amplified to $40 \mathrm{~W}$, corresponding to a single-stage gain of $20 \mathrm{~dB}$, with an optical to optical efficiency of $69 \%$. No indication of stimulated Brillouin scattering is observed, and the output is stable during frequency modulation of the seed laser.
\end{abstract}

Keywords: Photonic crystal fiber, fiber amplifier, narrow-linewidth, large-mode-area, all-solid fiber, high-power

\section{INTRODUCTION}

High-power narrow-linewidth fiber laser systems with diffraction-limited beam quality are applied in many areas of science and industry, including gravitational wave detection, ${ }^{1-3}$ trapping and cooling of atoms, ${ }^{4,5}$ and lidar technology. ${ }^{6}$ In many of these applications modulation of the seed laser frequency is required e.g. in order to lock it to an external reference. Typically, the systems are configured as a master oscillator power amplifier (MOPA), which consists of a low-power narrow-linewidth seed laser followed by several amplifier stages that scale the power. ${ }^{7}$

The main challenge to power scaling of narrow-linewidth is stimulated Brillouin scattering (SBS). This can be mitigated by applying external thermal gradients to the power scaling fiber amplifier or by tailoring its acoustic properties. ${ }^{8}$ However, the simplest way to mitigate SBS is to use short LMA fiber amplifiers. This makes PCFs amplifiers very attractive candidates for high-power narrow-linewidth amplification, since they can be designed with LMA cores that are SM at the operating wavelength.

Traditionally, LMA PCF designs include air holes whose diameters are adjusted to ensure a low effective index contrast between core and cladding, and thereby SM performance. However, splicing and interfacing of fibers with air holes is complicated. Recently, this was addressed by Papior et al. who reported the development of a LMA PCF amplifier without air holes and demonstrated SM high-power amplification of pulsed light. ${ }^{9}$ A similar PCF amplifier is considered in this work, but for narrow-linewidth amplification. The all-solid DC-250/30PM-Yb-FUD fiber fabricated by NKT Photonics A/S enables splicing with standard fusion splicers and thus integration of PCFs into all-fiber monolithic systems. ${ }^{10}$ These are more compact, robust against environmental perturbations, and reliable than systems based on free-space components.

In Sec. 2 a short description of the fiber and its passive properties is presented. In Sec. 3 the experimental demonstration of narrow-linewidth amplification with the fiber is reported.

\footnotetext{
*Corresponding author: jakmil@fotonik.dtu.dk
}

Fiber Lasers XVI: Technology and Systems, edited by Adrian L. Carter, Proc. of SPIE Vol. 10897, $1089728 \cdot$ @ 2019 SPIE · CCC code: 0277-786X/19/\$18 · doi: 10.1117/12.2506246 


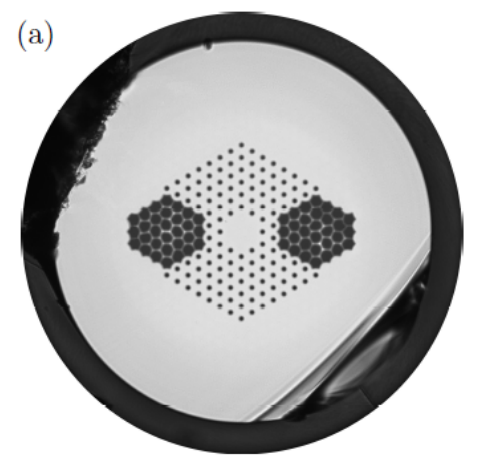

(b)

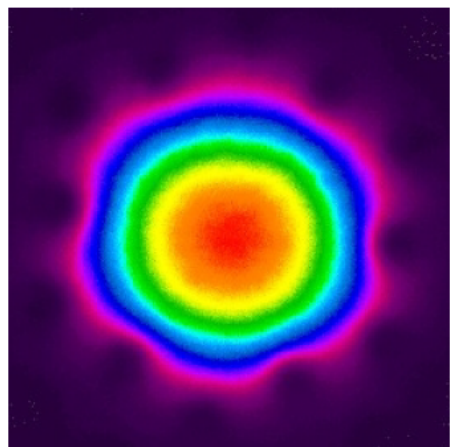

Figure 1. (a) Cross-sectional microscope image of the all-solid PCF. (b) Near-field image of the fiber mode for a coil diameter of $22 \mathrm{~cm}$.

\section{ALL-SOLID PHOTONIC CRYSTAL FIBER}

A cross-sectional microscope image of the DC-250/30-PM-Yb-FUD fiber is shown in Fig. 1(a). It has a $30 \mu \mathrm{m}$ diameter ytterbium-doped core surrounded by a periodic array of solid low-index inclusions that enable indexguiding of the core light. The fiber has a double-clad structure with an inner cladding diameter of $250 \mu \mathrm{m}$ and $\mathrm{NA}>0.46$. The pump light is confined to the inner cladding by a low-index polymer coating, which is itself surrounded by a protective coating (not shown in the figure). Two stress-applying elements induce birefringence that makes the fiber polarization-maintaining.

A detailed passive characterization of the fiber is given in Ref. 10. The fiber can be coiled with diameters down to the bend loss edge of approximately $19 \mathrm{~cm}$ of the fundamental mode in the slow axis polarization (parallel to the stress-applying elements). The bend loss edge of the fundamental mode in the fast axis polarization (perpendicular to the slow axis) is approximately a coil diameter of $25 \mathrm{~cm}$. Fig. 1(b) shows a near-field image for a coil diameter of $22 \mathrm{~cm}$ and a wavelength of $1064 \mathrm{~nm}$. A mode-field diameter of approximately $24 \mu \mathrm{m}$ is measured in this configuration where the fiber is single-mode. The fiber can be spliced to itself with a standard splice program with a loss of less than $0.2 \mathrm{~dB}$ for all wavelengths in the range $1005-1200 \mathrm{~nm}^{10}$

\section{ALL-SOLID PHOTONIC CRYSTAL FIBER FOR NARROW-LINEWIDTH AMPLIFICATION}

The all-solid LMA PCF amplifier is demonstrated for high-power amplification of $1064 \mathrm{~nm}$ light with a narrow linewidth of less than $20 \mathrm{kHz}$ in a counter-pumped free-space configuration shown schematically in Fig. 2. The

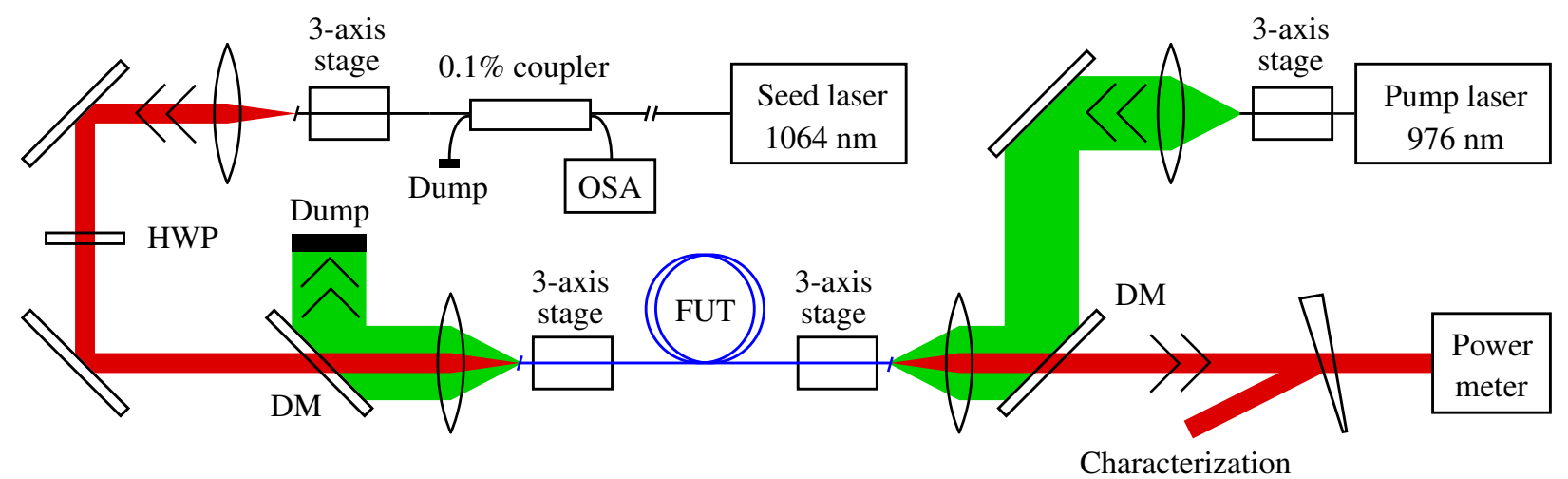

Figure 2. Schematic illustration of the free-space setup. OSA stands for optical spectrum analyzer, HWP for half-wave plate, DM for dichroic mirror, FUT for fiber under test (the DC-250/30-PM-Yb-FUD fiber), M for mirror, L for lens, and $\mathrm{W}$ is a silica wedge. Signal $(1064 \mathrm{~nm})$ light is indicated with red (black) and pump (976 nm) light with green (grey). 


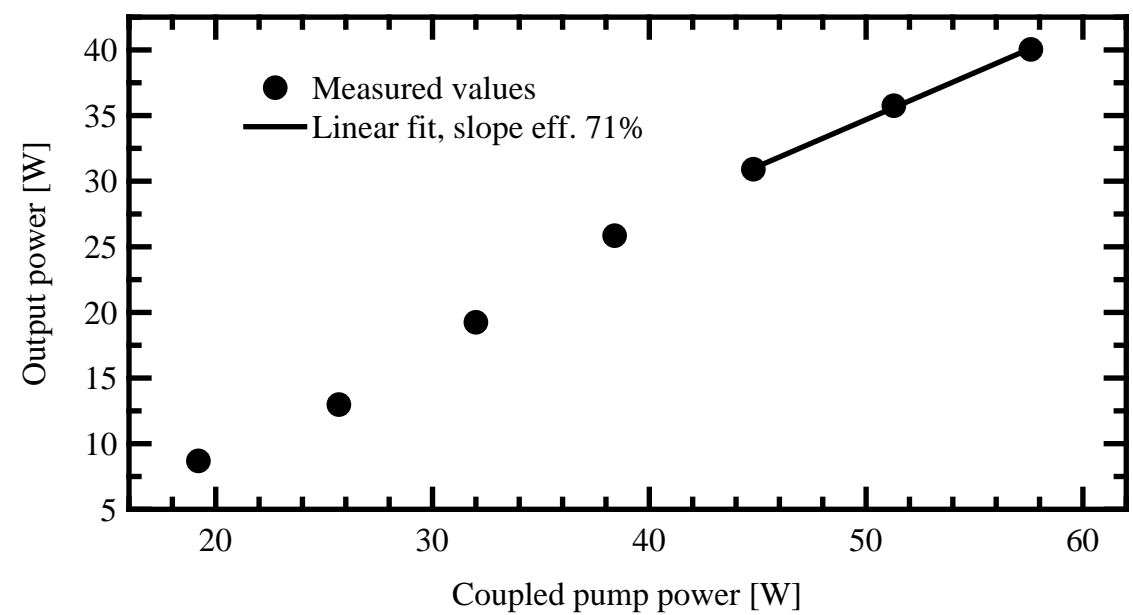

Figure 3. Output power as a function of coupled pump power for the $30 \mu \mathrm{m}$ core all-solid photonic crystal fiber amplifier of length $3.6 \mathrm{~m}$. A slope efficiency of $71 \%$ is achieved above coupled pump powers of $45 \mathrm{~W}$ (the three last measurements) where all the pump light has a wavelength of $976 \mathrm{~nm}$.

seed laser is based on a Koheras BASIK Y10 laser, which delivers $1064 \mathrm{~nm}$ light with a linewidth of less than $20 \mathrm{kHz} .{ }^{11}$ The seed light is coupled into the core of the DC-250/30-PM-Yb-FUD fiber with two three-axis stages, two mirrors and a half-wave plate such that the polarization is aligned with the stress elements of the fiber. Similarly the (unpolarized) pump is coupled into the inner cladding from the other end of the fiber with two three-axis stages and two mirrors, one of which is a dichroic mirror that reflects pump (976 nm) light and transmits the output signal $(1064 \mathrm{~nm})$ light. Any residual pump light, which is not absorbed but exits the fiber at the input end, is dumped by a dichroic mirror that reflects pump light and transmits signal light. A silica wedge in the output beam extracts a proportion of the light for characterization. The signal power at the fiber output end is calculated from the power measured by the power meter corrected for loss due to components between the fiber output end and the power meter.

The performance for $3.6 \mathrm{~m}$ of fiber is shown in Fig. 3. The pump wavelength is stabilized at $976 \mathrm{~nm}$ for coupled pump powers above approximately $45 \mathrm{~W}$. A coupled seed power of $380 \mathrm{~mW}$ is used, and an optical to optical efficiency of $69 \%$ is achieved for the maximum output power of $40 \mathrm{~W}$. A gain of $20 \mathrm{~dB}$ is thus achieved with a single amplification stage. A slope efficiency of $71 \%$ is obtained for coupled pump powers above $45 \mathrm{~W}$ where the pump wavelength is stabilized at $976 \mathrm{~nm}$.

Fig. 4 shows the output spectrum with a resolution of $1 \mathrm{~nm}$. The signal peak is approximately $45 \mathrm{~dB}$ above the amplified spontaneous emission (ASE), and the ratio of signal power to integrated ASE is $29 \mathrm{~dB}$.

The backward-reflected light was monitored with a $0.1 \%$ coupler connected to an optical spectrum analyzer, and no indication of SBS was observed. Furthermore, the output power is stable during frequency modulation (FM) of the seed laser. The FM stability was monitored by a fast detector in the characterization, both for a large modulation depth of $10 \mathrm{GHz}$ with a modulation frequency of $10 \mathrm{~Hz}$, a high modulation frequency of $5 \mathrm{kHz}$ with a modulation depth of $0.2 \mathrm{GHz}$, and modulation settings in between.

The results reported above were obtained in a free-space configuration but the DC-250/30-PM-Yb-FUD fiber is not restricted to free-space operation. It has been demonstrated by Christensen et al. in a monolithic forward-pumped setup for amplification of pulsed $1032 \mathrm{~nm}$ light up to $43 \mathrm{~W} .{ }^{10}$ The combination of this monolithic demonstration and the results reported in this work thus indicates that the DC-250/30-PM-Yb-FUD fiber enables few-stage monolithic MOPAs with narrow-linewidth output powers of several tens of watts. 


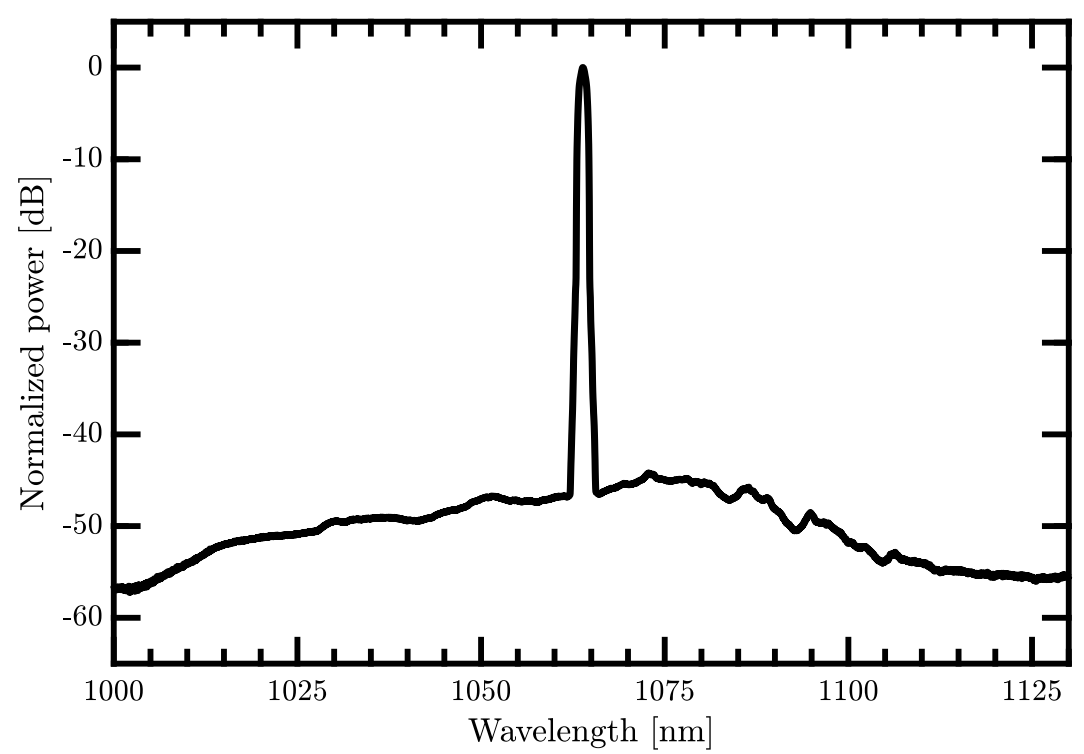

Figure 4. Output spectrum at $40 \mathrm{~W}$ output power with a resolution of $1 \mathrm{~nm}$.

\section{CONCLUSION}

In summary, an all-solid PCF with diffraction-limited beam quality is presented for high-power amplification of narrow-linewidth light. It is demonstrated in a free-space configuration as an amplifier with $40 \mathrm{~W}$ output power, a slope efficiency of $71 \%$, no detectable SBS, and a $29 \mathrm{~dB}$ ratio of signal power to integrated ASE.

The output is stable during frequency modulation of the seed laser. Moreover, the output corresponds to a high single-stage gain of $20 \mathrm{~dB}$, and the fiber is monolithic-compatible. It thus enables few-stage monolithic MOPAs with narrow-linewidth output powers of several tens of watts.

\section{REFERENCES}

[1] Suemasa, A., Shimo-oku, A., Nakagawa, K., and Musha, M., "Developments of high frequency and intensity stabilized lasers for space gravitational wave detector DECIGO/B-DECIGO," CEAS Space Journal 9(4), 485-491 (2017).

[2] Musha, M., "Space gravitational wave antenna DECIGO and B-DECIGO," CEAS Space Journal 9(4), 371-377 (2017).

[3] Tröbs, M., d'Arcio, L., Heinzel, G., and Danzmann, K., "Frequency stabilization and actuator characterization of an ytterbium-doped distributed-feedback fiber laser for LISA," J. Opt. Soc. Am. B 26(5), 1137-1140 (2009).

[4] Uetake, S., Yamaguchi, A., Kato, S., and Takahashi, Y., "High power narrow linewidth laser at $556 \mathrm{~nm}$ for magneto-optical trapping of ytterbium," Applied Physics B 92(1), 33-35 (2008).

[5] Andelkovic, Z., Cazan, R., Nörtershäuser, W., Bharadia, S., Segal, D. M., Thompson, R. C., Jöhren, R., Vollbrecht, J., Hannen, V., and Vogel, M., "Laser cooling of externally produced Mg ions in a Penning trap for sympathetic cooling of highly charged ions," Phys. Rev. A 87, 033423 (2013).

[6] Cariou, J.-P., Augere, B., and Valla, M., "Laser source requirements for coherent lidars based on fiber technology," Comptes Rendus Physique 7(2), 213-223 (2006). High power fiber lasers and amplifiers.

[7] Fu, S., Shi, W., Feng, Y., Zhang, L., Yang, Z., Xu, S., Zhu, X., Norwood, R. A., and Peyghambarian, N., "Review of recent progress on single-frequency fiber lasers [Invited]," J. Opt. Soc. Am. B 34(3), A49-A62 (2017).

[8] Robin, C., Dajani, I., and Pulford, B., "Modal instability-suppressing, single-frequency photonic crystal fiber amplifier with $811 \mathrm{~W}$ output power," Opt. Lett. 39(3), 666-669 (2014). 
[9] Papior, S. R., Weinrich, J., Johansen, M. M., Jakobsen, C., Michieletto, M., Triches, M., Kristensen, T., Olesen, A. S., Petersen, C., Andersen, T. V., Maack, M. D., and Alkeskjold, T. T., "Photonic crystal fiber technology for high-performance all-fiber monolithic ultrafast fiber amplifiers," Proc. SPIE 10512, 1051212 (2018).

[10] Christensen, S. L., Papior, S. R., Johansen, M. M., Hauge, J. M., Weirich, J., Jakobsen, C., Michieletto, M., Bondu, M., Triches, M., Alkeskjold, T. T., and Lægsgaard, J., "Photonic crystal fiber technology for monolithic single-mode large mode area all-solid amplifier," Proc. SPIE 10897, 10897-55 (2019).

[11] NKT Photonics, "Koheras BASIK low noise single-frequency OEM lasers." https://www.nktphotonics . com/lasers-fibers/product/koheras-basik-low-noise-single-frequency-oem-laser-modules/. (Accessed: 17 December 2018). 